\title{
Assessment the Quality of Services in Health Tourism using structural equation modeling (SEM) and confirmatory factor analysis (CFA): a case study in Mashhad, Iran
}

\section{Farhad Hemmati}

Islamic Azad University Sari Branch

Ghahraman Mahmoudi

Islamic Azad University Sari Branch

Fatemeh Dabbaghi ( $\sim$ hdd1625@gmail.com )

Islamic Azad University Sari Branch

\section{Research article}

Keywords: Mahshad, health tourism, confirmatory factor analysis, structural equation modeling

Posted Date: March 3rd, 2020

DOI: https://doi.org/10.21203/rs.3.rs-15796/v1

License: (c) (1) This work is licensed under a Creative Commons Attribution 4.0 International License.

Read Full License 


\section{Abstract}

Background: It is essential to improve the quality of services to satisfy health tourists. Thus, the present study was conducted to determine the relationship between quality of health services and tourism in Mashhad.

Methods: In this descriptive study, there were 120 subjects from the first population and 384 from the second. They completed a standard questionnaire with items related to demographic characteristics and tourism facilities in the five districts (north, south, east, west, and center) of Mashhad from 2017 to 2018. Data was analyzed using confirmatory factor analysis (CFA) and structural equation modeling (SEM). Spss21 and LISREL8.50 were used as the software.

Results: t-test results showed that the factor loadings were more than 1.96, so there was a correlation between the quality of services provided and health tourism in Mashhad.

Conclusion: According to the results, the importance of health tourism is so high that efforts for its development it in the region will lead to an all-comprehensive development. Hence, it is suggested that by strengthening the quality of services health tourism be improved in Mashhad.

\section{Background}

The tourism industry, as other service sectors, experiences increase in competition and the presence of new rivals every day, so that the significant growth of tourism activities clearly shows that tourism was one of the most important economic and social phenomena of the last century. In recent years, the arrival of private hotels with well-equipped infrastructure has made the competition more tangible. In such conditions where fairly similar services are presented in all hotels and each new service is quickly copied by rivals, creating special facilities for and relationships with the customers the hotels try to attract or keep is an effective step towards continuing the life of the organization and winning the competition (1). In Southeast Asia, the health sector is rapidly expanding, which can be attributed to the rapid growth of the private sector, especially health tourism, which is emerging as a lucrative business opportunity. Countries here invest on their popularity as tourism destinations by combining high-quality medical services at competitive prices with tourist packages. Some countries are creating relative advantage in providing services based on the organizational structure of their health system (2). As Khorasan and Mashhad, in particular, have good capacities to attract health tourists (domestic and foreign), but provinces and countries neighboring Khorasan lack the required potential in health sector (3). Considering the unique features of health tourism industry, such as the low cost of medicine and treatment, the existence of skilled specialists and experienced physicians, as well as the country's unmatched capabilities and attractions in the information system, it suffers significant problems regarding policy makers and managers, the lack of post-treatment care, lack of insurance policies in accordance with 
world standards and marketing plans, constant change in technology of the world, poor laws in medical crimes, and the appearance of medical centers and hospitals (4).

The quality of service significantly contributes to marketing issues regarding service differentiating and long-term market positioning for organizations and destinations or countries, so that they integrate the best service methods with customers' favorable perceptions (5). It is important to provide a package of services including the supply and demand of tourism services to increase the satisfaction and desire of tourists. Tourism facilities should be consistent with the motivations of the tourists. If the tourist is not satisfied with the quality of the service, he will not return to that destination anymore, and even worse, he will publish bad information and negative messages on the site visited (6). Continuation of the sustained growth of tourism in the destination in line with service-profit chain depends on making the tourists loyal by the sense of satisfaction with the quality of services provided. The value of services at a destination will satisfy the tourist, the satisfaction of the tourist will lead to the loyalty of the tourist, and ultimately the loyalty of the tourist will result in profit and growth of the area (7).

Majid et al. (2017) stated that natural treatments by medical tourists as well as allopathic therapies (a Western-based surgical and medicine-based approach) and tourist attractions are considered. However, despite the existence of allopathic treatment system, the emerging medical system, where there is no alternative to treatment of T\& CM, is not still available. (8). Madžar et al. (2016) stated that participation in the theory and practice of quality management services is a practical contribution based on the enormous economic potential that the increase in the quality of health tourism can have in the Republic of Croatia (9). Nouri and Kargari (2016) stated that based on this algorithm, employee behavior, social security and communication are, respectively, the most important factors in medical tourism attractions (10). Szymanska (2015) stated that innovation in tourism is in response to the growing public demand for a long life, staying healthy, and maintaining beauty and goodness. The purpose is to create a theoretical model of the health-tourism innovation system. Moreover, the purpose is to present the results of a survey of experts conducted in two rounds using Delphi method. The result of the research is the construction of three different models of innovation in health tourism (11). Abd Manaf et al. (2014) identified the three aspects of the quality of Malaysian medical tourism services: the quality of medical employees, support for the quality of services and the quality of administrative services. The quality of medical employees was predictive of all three variables: patient satisfaction, perceived value, and future intention for treatment (12). Unfortunately, there are many shortcomings in the quality of services provided in this industry until being a good host for tourists and a good profit for Iran. Hence, according to the previous studies, the present study was conducted to examine the quality of services in health tourism in Mashhad.

\section{Materials And Methods}

The study was applied in terms of purpose. It was a field study regarding the degree of importance and the control of the variables, and survey in terms of data collection, which was conducted during 20172018. Moreover, the study was descriptive-analytical study in terms of data analysis. The paper tried to 
compare what is relevant to the quality of health tourism services in domestic and foreign texts in hospitals and other organizations to identify the relevant patterns. Furthermore, the appropriate pattern was developed using SEM and hospital experts' opinions.

The population for the first part (studying the factors) was the heads, managers and experts of hospitals including physicians, faculty members of health-service management, senior experts in health-service management, senior experts and hospital specialists in the five regions (north, south, east, west and center) of Mashhad. SEM was performed based on Kaiser-Meyer-Olkin (KMO). Thus, if p-value $<0.05$ is the sufficient number of the sample, the sampling is done on 20 to 10 times the number of variables to determine the sample (13). The whole city is divided into five regions and based on multi-stage random clustering sampling each region had 24 subjects based on the number of variables that was 120 people. In doing so, they were selected based on random stratified sampling in the hospital. Furthermore, this information was compared and matched with the six regions based on World Health Organization (WHO). Two countries were selected from all six regions (Africa, America, Eastern Mediterranean, Europe, Southeast Asia, Western Pacific) as members of WHO active in health tourism (for the first population).

Due to the unlimited population of the second part (health tourism), according to the Cochran's sampling formula, 384 subjects were selected as samples. Given the five regions (north, south, east, west and center) of Mashhad for health tourism, the share of each region was 77 (for the second population).

A questionnaire was used for data collection. The questionnaire designed for this study had three parts: part one included demographic information of respondents such as gender, age, level of education and work experience. Part 2 included the main questions of the surveys for service quality. This questionnaire was adapted from Kassidi (2014). Part 3 included the main questions of health tourism surveys. This questionnaire was adapted from Goodarzi et al. Scoring was based on a 5-option Likert scale as totally disagree (1), disagree (2), no idea (3), agree (4) and totally agree (5). The health tourism questionnaire had nine questions where the people select their options. Thirty questionnaires were distributed among the samples to determine the reliability before its full distribution, which was more than 0.7 and was acceptable. Moreover, after a week, the questionnaires were distributed among the subjects again, and the alpha coefficient was 0.73 . Using SPSS 21 and Lisrel 8 software along descriptive and inferential statistical methods, the study performed the statistical analyses and hypothesis testing.

Among the ethical considerations of the study, obtaining the consent and cooperation of the officials working in the educational hospitals affiliated to the Ministry of Health and Medical Education, respecting the rights of each subject including writing the names of the authors and scholars whose works are used in the study can be cited. Moreover, the expert respondents were ensured for preserving the confidentiality of the information by the researcher, the actual reflection of the results and avoiding any prejudice in the conclusion, providing the results to respondents upon request.

The inclusion criterion was being chief executives, experts and specialists in hospitals, doctors, faculty members of health services management, senior healthcare management experts, senior experts and 
hospital experts, and the exclusion criterion were being from administrative employees and the clients. The acceptable error rate was 0.05 .

\section{Results}

According to the results, $52 \%$ of the employees were females, $72 \%$ male tourists, $35 \%$ of the employees were in the age group 31-40 years old and $59 \%$ of the tourists were in the same age group. Furthermore, $38 \%$ of the employees and $53 \%$ of the tourists had bachelor's degrees. In addition, $52 \%$ of employees were in the range of $11-15$ years of work history (Table 1 ).

Table 1

Frequency of distribution, frequency percent and the cumulative percent of demographic variables of the respondents (the employees and tourists)

\begin{tabular}{|lllll|}
\hline $\begin{array}{l}\text { Frequency } \\
\text { Variables }\end{array}$ & $\begin{array}{l}\text { Observed } \\
\text { frequency }\end{array}$ & $\begin{array}{l}\text { Observed } \\
\text { percentage }\end{array}$ & $\begin{array}{l}\text { Cumulative } \\
\text { percent }\end{array}$ \\
\hline Gender (employees) & Female & 62 & 52 & 48 \\
\hline Age (employees) & $\begin{array}{l}31- \\
40 \text { years }\end{array}$ & 42 & 35 & 67 \\
\hline $\begin{array}{l}\text { Educational level } \\
\text { (employees) }\end{array}$ & bachelor's & 46 & 38 & 89 \\
$\begin{array}{l}\text { Work experience } \\
\text { (employees) }\end{array}$ & $\begin{array}{l}11- \\
15 \text { years }\end{array}$ & 63 & 52 & 65 \\
\hline $\begin{array}{l}\text { Gender (tourists) } \\
\text { Male }\end{array}$ & 276 & 72 & 72 \\
\hline $\begin{array}{l}\text { Age (tourists) } \\
40 \text { years }\end{array}$ & 228 & 59 & 97 \\
\hline $\begin{array}{l}\text { Educational level } \\
\text { (tourists) }\end{array}$ & bachelor's & 204 & 53 & 66 \\
\hline
\end{tabular}

Given the suitability of the size of KMO sampling adequacy and Bartlett's Test of Sphericity Significance, the data is appropriate for factor analysis. Based on these two tests, time series data are appropriate for factor analysis: $\mathrm{KMO}$ is more than 0.6 and close to one and the significance level of Bartlett's is less than 0.05 . If the value of this statistic is more than 0.7 , the correlations are very suitable for factor analysis. If it is between 0.5 and 0.69 , more care should be taken, and if it is less than 0.5 , it is not suitable for factor analysis (Table 2). 
Table 2

The size of KMO and the result of Bartlett's Test of Sphericity

\begin{tabular}{|lll|}
\hline Index & Suitable value & The value obtained \\
\hline KMO & More than 0.7 & 0.84 \\
\hline Bartlett's significance & Less than 0.05 & 0.000 \\
\hline Test result & & Suitable \\
\hline
\end{tabular}

According to the output of LISREL, the fit index values obtained are appropriate and all the numbers and factor loadings are more than 0.3 and desirable (Fig. 1).

In SEM, all numbers and factor loadings are more than 0.3 and desirable (Fig. 2).

Table 3

Fitness indices for the research model

\begin{tabular}{|lllllllll|}
\hline Fitness index & $\chi^{2} / \mathbf{d f}$ & SRMR & RMSEA & GFI & AGFI & NFI & CFI & IFI \\
\hline Fitness for the research model & 4.1 & 0.04 & 0.023 & 0.92 & 0.91 & 0.93 & 0.92 & 0.75 \\
\hline Acceptable domain & $1-5$ & $<0.05$ & $<0.5$ & $>0.9$ & $>0.9$ & $>0.9$ & $>0.9$ & $0-1$ \\
\hline
\end{tabular}

The results of the above table show that the research model is in good condition in terms of fitting indices and Root Mean Square Error of Approximation whose domain of acceptance is $0.5>$ is 0.023 and very good. Thus, considering all the indices and the calculated fitness indices, one can state that fitness indices for the research model have good fit (Table 3).

Considering the t test, all the value of $t$ statistic - the significance of the observed correlations - in this model is more than 1.96 and accepted (Fig. 2).

\section{Discussion And Conclusion}

The results showed that the sample (number of the respondents) is sufficient for factor analysis. In addition, the significance level of Bartlett's test showed that factor analysis is suitable for identifying the structure of the factor model. SEM and correlation, including the relationship between the qualities of service provided and Mashhad's health tourism, was confirmed like the similar studies. According to LISREL output, the values of fit index were appropriate and all the numbers and factor loadings are acceptable. Thus, the research model is in good condition in terms of fitness indices. There was a relationship between the quality of the services provided and Mashhad Health Tourism. Madžar et al. (2016) stated that participation in the theory and practice of quality management services is a practical contribution based on the enormous economic potential that the increase in the quality of health tourism can have in the Republic of Croatia (9). Abd Manaf et al. (2014) identified the quality of medical 
employees, support for the quality of services and the quality of administrative services where the quality of medical employees was predictive of all three variables: patient satisfaction, perceived value, and future intention for treatment (12). Gholami et al. (2016) stated that improving the trust of medical tourists regarding the services provided by hospitals is an effective factor in increasing their level of satisfaction (14). Gholipour (2016) stated that Ahwaz hospitals are required to focus more on the welfare facilities of tourists for the development of medical tourism industry (4). These results are in line with the result of the present study.

In spite of the great potential of Mashhad to attract tourists, it faces some deficiencies in infrastructure and they less consider many places of tourism in Mashhad for various reasons, including low level of service quality according to the tourists' mental image. Thus, special attention is required to be paid to the basic planning for improving the quality of services provided by tourist attractions, increasing the satisfaction of tourists and increasing their stay in the city. When the tourism industry is seen as a service activity, one should consider providing services to many experts with different skills and effectiveness. In the current competitive market, surely the regions and the countries win the competition that render services with a higher standard according to the level of customer expectations (tourist), which means that with better training to the employees, they provide better services with higher efficiency. Here, identifying the strengths and weaknesses of this industry can be considered as a major strategy in longterm planning in reducing the shortcomings and strengthening the tourism industry. Thus, it is necessary to communicate with tourists during and even after the completion of the tourist trips to be informed about their satisfaction and opinion. Moreover, holding festivals increases the satisfaction of tourists. Thus, one can expect that the mental image of the tourist from the destination will improve and so will the loyalty to the destination. Furthermore, as a part of their competitiveness strategies, tourism organizations must recognize that the quality of tourism services is a key introduction to the mental image of the tourism destination and a necessary part in achieving tourists' loyalty to the destination. Thus, tourist organizations in destinations should provide an attractive and enjoyable environment for tourists as a key element for future visits and promotion of tourist sites visited by loyal tourists. Providing quality tourism services and ensuring strong customer satisfaction should be considered. Providers of tourism services should follow accountability and should be trustworthy advisers to their customers. Some gifts and souvenirs should be presented to the tourists as a means to make them remember the tourism destination, full security of tourists should be secured in residential and tourist destinations, and the residential places of the tourists should have the beauty and health standards. Thus, observance of these factors will increase the trust of tourists and their return.

Every study has some limitations, and the limitations of this study were the lack of willingness of some respondents and the lack of resources similar to the subject of the study.

\section{Declarations}

\section{Acknowledgments}


Hereby, we appreciate the cooperation and assistance of the authorities of the Islamic Azad University of Sari, the hospitals under study throughout Iran and the experts of the hospitals.

\section{Funding:}

The author (s) received no specific funding for this work.

\section{Authors' contributions:}

F.D. provided the idea for this work and designed. F.H. ;G.M. data gathering. F.H ; and F.D. Wrote the main manuscript text, discussed the scientific idea and reviewed the manuscript. All authors participated in writing the manuscript. All authors reviewed the manuscript. All authors contributed to the scientific discussion. These authors jointly supervised this work.

\section{Ethical approval and consent to participate:}

This article is a part of the research plan approved by committee of Islamic Azad University of Sari registered under the Ethics Code No. IR.IAU.CHALUS.REC.1396-43.

\section{Consent for publication:}

Not applicable

\section{Competing interests}

The authors of this article declare that they have no conflict of interests.

\section{References}

1. Hemmati F, Dabbaghi F, Mahmoudi Gh. Investigating the impact of information technology on the status of health tourism in Mashhad, Iran. Revista Publicando. 2018; 15 (1): 54-65.

2. Hemmati F, Dabbaghi F, Mahmoudi Gh. Iran's need for medical tourism development. Journal of Research in Medical and Dental Science. 2018; 6 (1): 269-273.

3. Hemmati F, Dabbaghi F, Mahmoudi Gh. Human capital status in Mashhad health tourism. Revista Publicando 2017; 12 (1): 410-420.

4. Gholipour, M. Analysis of the Quality of Medical Tourist Services in Khuzestan Province in 2015: Ahvaz Jundishapur University of Medical Sciences \& Health Services; 2016

5. Heidarzadeh, K., Najafi, K., Hosseini, S.A. The efect of the quality of tourism services on loyalty to the destination of tourism due to the mediating role of the image of the destination of tourism and the satisfaction of tourists. Quarterly Journal of Tourism Management Studies. 2017; 12 (40): 115-153.

6. Langvinine N. Changing patterns in the health tourism services sector in Lithuania. Procedia - Social and Behavioral Sciences. 2014; 156: 310 -316. 
7. Loncaric D, Loncaric D, Markovic S. HEALTH TOURISM, CUSTOMER SATISFACTION AND QUALITY OF LIFE: THE ROLE OF SPECIALTY HOSPITALS. Tourism in Southern and Eastern Europe. 2015;3:159-73.

8. Majeed S, Lua Ch, Javed T. The journey from an allopathic to natural treatment approach: A scoping review of medical tourism and health systems. European Journal of Integrative Medicine. 2017;16:22-32.

9. Madžar T, Lazibat T, Mikulić J. MEASURING SERVICE QUALITY IN HEALTH TOURISM. POSLOVNA IZVRSNOST ZAGREB. 2016;1.

10. Noori F, Kargari M. Iran's Medical Tourism Development Model in Cardiac Surgery. International Journal of Travel Medicine and Global Health. 2016:57-64.

11. Szymanska E. Construction of the Model of Health Tourism Innovativeness. Procedia - Social and Behavioral Sciences. 2015;213:1008 -1014.

12. Abd Manaf,N H, Hussin H,Jahn Kassim P N, AlaviR, Dahari Z. Medical tourism service quality: finally some empirical findings. Total Quality Management \& Business Excellence. 2015; 26(9-10).

13. Human HA. Structural Equation Modeling Using Laser Software. Tehran: Organization for the Study and Compilation of Humanities Books of Universities; 2016.

14. Gholami M., Jabari, A.R., Kavousi, Z., Chamanpara, P. Evaluating the attitude of leisure travelers towards the quality of services in Shiraz hospitals using the SERVQUAL model. Health Information Management. 2016; 13 (2): 145-152.

\section{Figures}




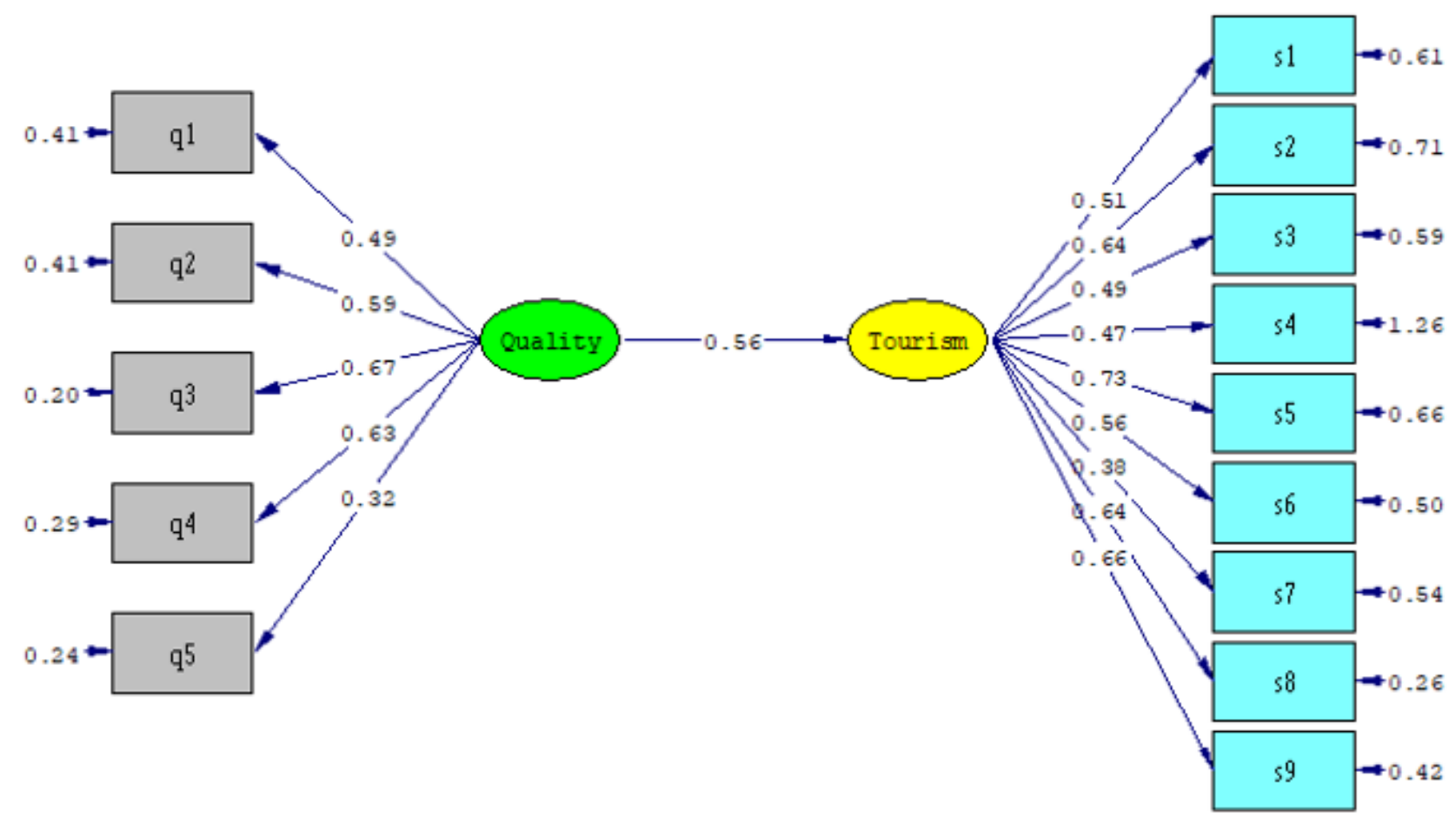

Chi-Square $=315.40, d f=76, P-v a l u e=0.00000$, RMSEA $=0.023$

\section{Figure 1}

Standard factor loadings for of the structural model

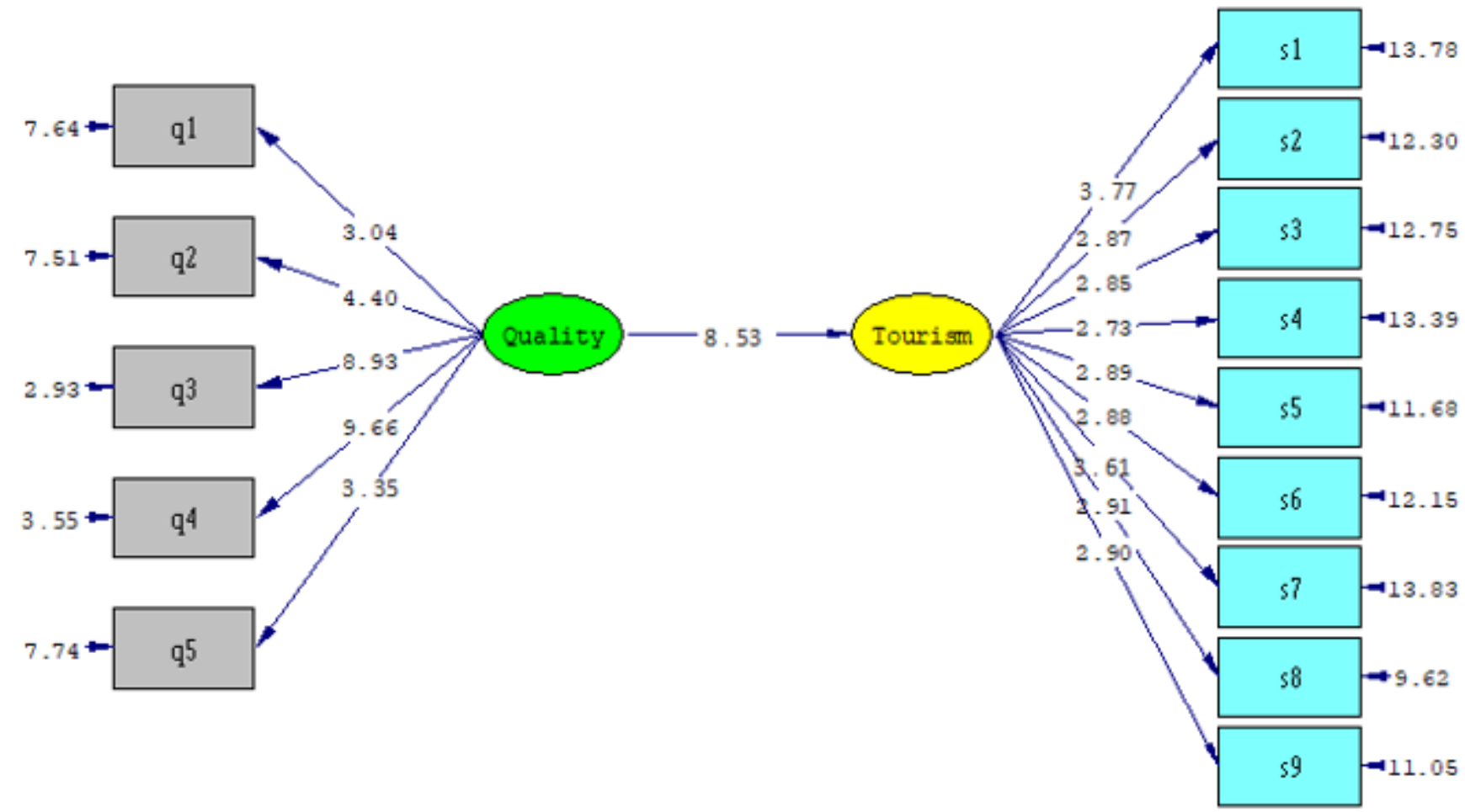

Chi-Square $=315.40, d f=76, \mathrm{P}-$ value $=0.00000$, RMSEA $=0.023$

Figure 2 
Factor loadings of t-value statistics Structural model of the study 